\title{
The Individual Life Cycle and Economic Growth: An Essay on Demographic Macroeconomics
}

\author{
Ben J. Heijdra • Jochen O. Mierau
}

Published online: 25 December 2010

(C) The Author(s) 2010. This article is published with open access at Springerlink.com

\begin{abstract}
We develop a demographic macroeconomic model that captures the salient life-cycle features at the individual level and, at the same time, allows us to pinpoint the main mechanisms at play at the aggregate level. At the individual level the model features both age-dependent mortality and productivity and allows for less-than-perfect annuity markets. At the aggregate level the model gives rise to single-sector endogenous growth and includes a Pay-As-You-Go pension system. We show that ageing generally promotes economic growth due to a strong savings response. Under a defined benefit system the growth effect is still positive but lower than under a defined contribution system. Surprisingly, we find that an increase in the retirement age dampens the economic growth expansion following a longevity shock.
\end{abstract}

Keywords Annuity markets - Pensions - Retirement - Endogenous growth · Overlapping generations · Demography

JEL Classification D52 - D91 · E10 - J20

B. J. Heijdra $(\varangle) \cdot$ J. O. Mierau

Faculty of Economics and Business, University of Groningen,

P.O. Box 800, 9700 AV Groningen, The Netherlands

e-mail: info@heijdra.org

J. O. Mierau

e-mail: j.o.mierau@rug.nl

B. J. Heijdra

IHS, Vienna, Austria

B. J. Heijdra

CESifo, Munich, Germany

B. J. Heijdra · J. O. Mierau

Netspar, Tilburg, The Netherlands 


\section{Introduction}

In contrast to its Keynesian counterpart, neoclassical macroeconomics prides itself that it is rigorously derived from solid microeconomic foundations. Indeed, the canonical neoclassical macro model is typically based on the aggregate behaviour of infinitelylived rational agents maximizing their life-time utility. But, really, how micro-founded are these models? Is it proper to suppose that the aggregate economy acts as though it were one agent? Is it proper to assume that individuals live forever? The commonplace reaction to these questions is, of course, to ignore them under the Friedman norm that if the model is able to replicate reality then it must be fine.

The neoclassical model, however, is not able to replicate reality. This simple observation induced a long line of research trying to incorporate features into large macroeconomic models that would bring them closer to reality. To no avail it seems, for Sims (1980) went so far as to argue that macroeconomics is so out of touch with reality that a simple "measurement without theory" approach seemed to outperform the most sophisticated models. Measurement without theory, however, also implies outcomes without policy implications. For the mechanisms at play remain hidden from view.

In a seminal contribution Blanchard (1985) introduced the most basic of human features into an otherwise standard macroeconomic model and came to a surprising conclusion. If non-altruistic individuals are finitely lived, then one of the key theorems of neoclassical thought - the Ricardian equivalence theorem-no longer holds. Innovative as it was, the Blanchard model still suffers from serious shortcomings. For instance, it assumes that individuals have a mortality rate that is independent of their age. That is, a 10-year old child and a 969-year old Methuselah have the same probability of dying (indeed in Blanchard's model there is not even an upper limit for the age of individuals). Furthermore, it assumes that perfect life-insurance markets exist so that, from the point of view of the individual, mortality hardly matters much at all.

In reaction to Blanchard's analysis, a huge body of literature evolved introducing additional features aimed at improving the description of the life-cycle behaviour of the individual who stands at the core of the model. As computing power became more readily available, the so-called computable general equilibrium (CGE) approach was close to follow. ${ }^{1}$ The outward shift in the computational technology frontier made ever more complex models feasible but Sims (1980) critique seemed to have had a short echo for within foreseeable time these models had again become so complex that the mechanisms translating microeconomic behaviour into macroeconomic outcomes were lost in aggregation and details of the solution algorithm.

The challenge thus remains to construct macroeconomic models that, on the one hand, are solidly founded in the microeconomic environment of the individual agent and, on the other hand, are able to show to the analyst which main mechanisms are at play. In this paper we contribute our part to this challenge. That is, we construct a tractable macroeconomic model that can replicate basic facts of the individual life-cycle

\footnotetext{
1 The classic reference in this area is Auerbach and Kotlikoff (1987). For a recent survey of stochastic CGE overlapping generations models, see Fehr (2009).
} 
and, at the same time, clearly shows which mechanisms drive the two-way interaction between microeconomic behaviour and macroeconomic outcomes.

The advantage of our approach over the Blanchard (1985) framework is that we can replicate the most important life-cycle choices that an individual makes. In earlier work (Heijdra and Mierau 2009) we show that conclusions concerning credit market imperfections may be grossly out of line if such life-cycle features are ignored. The advantage of our approach over the CGE framework is that we retain the flexibility necessary to analyze which factors are driving the relationship between individuals and their macroeconomic environment. Although CGE models can account for numerous institutional traits that are beyond our model, such models fare worse at identifying which mechanisms are at play.

In order to incorporate longevity risk in our model we make use of the demographic macroeconomic framework developed in Heijdra and Romp (2008) and Heijdra and Mierau $(2009,2010){ }^{2}$ We assume that annuity markets are imperfect. This leads individuals to discount future felicity by their mortality rate which is increasing in age. Hence, individuals have a hump-shaped consumption profile over their life-cycle. The empirically observed hump-shaped consumption profile for individuals is further studied for the Netherlands by Alessie and de Ree (2009). In contrast to our earlier work we assume that labour supply and the retirement age are exogenous.

At the aggregate level our model builds on the insights of Romer (1989) and postulates the existence of strong inter-firm investment externalities. These externalities act as the engine behind the endogenous growth mechanism. Furthermore, we introduce a government pension system in order to study the role of institutional arrangements on the relationship between ageing and economic growth. In particular we study a Pay-As-You-Go system that may be either financed on a defined benefit or a defined contribution basis. In addition the government may use the retirement age as a policy variable.

We use this model to study how ageing relates to economic growth and what role there is for government policy. We find that, in principle, ageing is good for economic growth because it increases the incentive for individuals to save. However, if a defined benefit system is in place the higher contributions necessary to finance the additional pensioners will reduce individual savings and thereby dampen the growth increase following a longevity shock. In order to circumvent this reduction in growth the government could opt to introduce a defined contribution system in which the benefits are adjusted downward to accommodate the increased dependency ratio. Surprisingly, we find that if the government increases the retirement age such that the old age dependency ratio remains constant economic growth drops compared to both the defined benefit and the defined contribution system. This is due to an adverse savings effect following from the shortened retirement period. We study the robustness of our results to accommodate different assumptions concerning future mortality and we allow for a broader definition of the pension system that also incorporates health care costs.

\footnotetext{
2 In addition to the above mentioned references important recent contributions to the field of demographic macroeconomics have been, inter alia, by Boucekkine et al. (2002) and d'Albis (2007).
} 
The remainder of the paper is set-up as follows. The next Section introduces the model and discusses how we feed in a realistic life-cycle. Section 3 analyses the steadystate consequences of ageing and provides some policy recommendations. Section 4 concludes.

\section{Model}

Our model makes use of the insights developed in Heijdra and Mierau (2009, 2010). We extend our earlier analysis by incorporating a simple PAYG pension system but we simplify it by assuming that labour supply and the retirement age are exogenous. In the remainder of this section we discuss the main features of the model. For details the interested reader is referred to our earlier papers.

On the production side the model features inter-firm externalities which constitute the foundation for the endogenous growth mechanism. On the consumption side, the model features age-dependent mortality and labour productivity and allows for imperfections in the annuity market. In combination, these features ensure that the model can capture realistic life-cycle aspects of the consumer-worker's behaviour. Throughout the paper we restrict attention to the steady-state.

\subsection{Firms}

The production side of the model makes use of the insights of Romer (1989, pp. 89-90) and postulates the existence of sufficiently strong external effects operating between private firms in the economy. There is a large and fixed number, $\mathcal{N}$, of identical, perfectly competitive firms. The technology available to firm $i$ is given by:

$$
Y_{i}(t)=\Omega(t) K_{i}(t)^{\varepsilon} N_{i}(t)^{1-\varepsilon}, \quad 0<\varepsilon<1,
$$

where $Y_{i}(t)$ is output, $K_{i}(t)$ is capital use, $N_{i}(t)$ is the labour input in efficiency units, and $\Omega(t)$ represents the general level of factor productivity which is taken as given by individual firms. The competitive firm hires factors of production according to the following marginal productivity conditions:

$$
\begin{aligned}
w(t) & =(1-\varepsilon) \Omega(t) \kappa_{i}(t)^{\varepsilon}, \\
r(t)+\delta & =\varepsilon \Omega(t) \kappa_{i}(t)^{\varepsilon-1},
\end{aligned}
$$

where $\kappa_{i}(t) \equiv K_{i}(t) / N_{i}(t)$ is the capital intensity. The rental rate on each factor is the same for all firms, i.e. they all choose the same capital intensity and $\kappa_{i}(t)=\kappa(t)$ for all $i=1, \ldots, \mathcal{N}$. This is a very useful property of the model because it enables us to aggregate the microeconomic relations to the macroeconomic level. 
Generalizing the insights Romer (1989) to a growing population, we assume that the inter-firm externality takes the following form:

$$
\Omega(t)=\Omega_{0} \cdot \kappa(t)^{1-\varepsilon},
$$

where $\Omega_{0}$ is a positive constant, $\kappa(t) \equiv K(t) / N(t)$ is the economy-wide capital intensity, $K(t) \equiv \sum_{i} K_{i}(t)$ is the aggregate capital stock, and $N(t) \equiv \sum_{i} N_{i}(t)$ is aggregate employment in efficiency units. According to Eq. 4, total factor productivity depends positively on the aggregate capital intensity, i.e. if an individual firm $i$ raises its capital intensity, then all firms in the economy benefit somewhat as a result because the general productivity indicator rises for all of them.

Using Eq. 4, Eqs. 1-3 can now be rewritten in aggregate terms:

$$
\begin{aligned}
Y(t) & =\Omega_{0} K(t), \\
w(t) N(t) & =(1-\varepsilon) Y(t), \\
r(t) & =r=\varepsilon \Omega_{0}-\delta,
\end{aligned}
$$

where $Y(t) \equiv \sum_{i} Y_{i}(t)$ is aggregate output and we assume that capital is sufficiently productive, i.e. $r>\pi$, where $\pi$ is the rate of population growth (see below). The aggregate technology is linear in the capital stock and the interest is constant.

\subsection{Consumers}

\subsubsection{Individual behaviour}

We develop the individual's decision rules from the perspective of birth. Expected lifetime utility of an individual born at time $v$ is given by:

$$
\mathbb{E} \Lambda(v, v) \equiv \int_{v}^{v+D} \frac{C(v, \tau)^{1-1 / \sigma}-1}{1-1 / \sigma} \cdot e^{-\rho(\tau-v)-M(\tau-v)} d \tau
$$

where $C(v, \tau)$ is consumption, $\sigma$ is the intertemporal substitution elasticity $(\sigma>0), \rho$ is the pure rate of time preference $(\rho>0), D$ is the maximum attainable age for the agent, and $e^{-M(\tau-v)}$ is the probability that the agent is still alive at some future time $\tau(\geq v)$. Here, $M(\tau-v) \equiv \int_{0}^{\tau-v} \mu(s) d s$ stands for the cumulative mortality rate and $\mu(s)$ is the instantaneous mortality rate of an agent of age $s$.

The agent's budget identity is given by:

$$
\begin{aligned}
\dot{A}(v, \tau)= & r^{A}(\tau-v) A(v, \tau)+w(v, \tau) L(v, \tau)-C(v, \tau) \\
& +P R(v, \tau)+T R(v, \tau),
\end{aligned}
$$

where $A(v, \tau)$ is the stock of financial assets, $r^{A}(\tau-v)$ is the age-dependent annuity rate of interest rate, $w(v, \tau) \equiv E(\tau-v) w(\tau)$ is the age-dependent wage rate, 
$E(\tau-v)$ is exogenous labour productivity, $L(v, \tau)$ is labour supply, $P R(v, \tau)$ are payments received from the public pension system, and $T R(v, \tau)$ are lump-sum transfers (see below). Labour supply is exogenous and mandatory retirement takes place at age $R$. Since the time endowment is unity, we thus find:

$$
L(v, \tau)=\left\{\begin{array}{l}
1 \text { for } 0 \leq \tau-v<R \\
0 \text { for } R \leq \tau-v<D
\end{array}\right.
$$

Along the balanced growth path, labour productivity grows at a constant exponential rate, $g$ (determined endogenously below), and as a result individual agents face the following path for real wages during their active period (for $0 \leq \tau-v \leq R$ ):

$$
w(v, \tau)=w(v) E(\tau-v) e^{g(\tau-v)} .
$$

The wage is thus multiplicatively separable in vintage $v$ and in age $\tau-v$. The wage at birth acts as an important initial condition facing an individual.

There is a simple PAYG pension system which taxes workers and provides benefits to retirees:

$$
P R(v, \tau)= \begin{cases}-\theta w(v, \tau) & \text { for } 0 \leq \tau-v<R \\ \zeta w(\tau) & \text { for } R \leq \tau-v<D\end{cases}
$$

where $\theta(0<\theta<1)$ is the contribution rate and $\zeta$ is the benefit rate $(\zeta>0)$. Under a defined contribution (DC) system, $\theta$ is exogenous and $\zeta$ adjusts to balance the budget (see below). The opposite holds under a defined benefit (DB) system. Finally, we postulate that lump-sum transfers are age-independent:

$$
\operatorname{TR}(v, \tau)=z \cdot w(\tau)
$$

where $z$ is endogenously determined via the balanced budget requirement of the redistribution scheme (see below).

Like Yaari (1965). we postulate the existence of annuity markets, but unlike Yaari we allow the annuities to be less than actuarially fair. Since the agent is subject to lifetime uncertainty and has no bequest motive, he/she will fully annuitize so that the annuity rate of interest facing the agent is given by:

$$
r^{A}(\tau-v) \equiv r+\lambda \mu(\tau-v), \quad(\text { for } 0 \leq \tau-v<D)
$$

where $r$ is the real interest rate (see Eq. 7), and $\lambda$ is a parameter $(0<\lambda \leq 1)$. The case of perfect, actuarially fair, annuities is obtained by setting $\lambda=1$. One of the reasons why $\lambda$ may be strictly less than unity, however, is that annuity firms may possess some market power allowing them to make a profit by offering a less than actuarially fair annuity rate. We assume that the profits of annuity firms are taxed away by the government and redistributed to households in a potentially age-dependent lump-sum 
fashion (see below). We shall refer to $1-\lambda$ as the degree of imperfection in the annuity market. $^{3}$

The agent chooses time profiles for $C(v, \tau)$ and $A(v, \tau)$ (for $v \leq \tau \leq v+D)$ in order to maximize Eq. 8, subject to (i) the budget identity (Eq. 9), (ii) a NPG condition, $\lim _{\tau \rightarrow \infty} A(v, \tau) \cdot e^{-r(\tau-v)-\lambda M(\tau-v)}=0$, and (iii) the initial asset position at birth, $A(v, v)=0$. The optimal consumption profile for a vintage- $v$ individual of age $u(0 \leq u \leq D)$ is fully characterized by the following equations:

$$
\begin{aligned}
C(v, v+u)= & C(v, v) \cdot e^{\sigma[(r-\rho) u-(1-\lambda) M(u)]}, \\
\frac{C(v, v)}{w(v)}= & \frac{1}{\int_{0}^{D} e^{(\sigma-1)[r s+\lambda M(s)]-\sigma[\rho s+M(s)]} d s} \cdot \frac{H(v, v)}{w(v)}, \\
\frac{H(v, v)}{w(v)}= & (1-\theta) \int_{0}^{R} E(s) e^{-(r-g) s-\lambda M(s)} d s+\zeta \int_{R}^{D} e^{-(r-g) s-\lambda M(s)} d s \\
& +z \int_{0}^{D} e^{-(r-g) s-\lambda M(s)} d s .
\end{aligned}
$$

The intuition behind these expressions is as follows. Equation 15 is best understood by noting that the consumption Euler equation resulting from utility maximization takes the following form:

$$
\frac{\dot{C}(v, \tau)}{C(v, \tau)}=\sigma \cdot[r-\rho-(1-\lambda) \mu(\tau-v)]
$$

By using this expression, future consumption can be expressed in terms of consumption at birth as in Eq. 15. In the absence of an annuity market imperfection $(\lambda=1)$, consumption growth only depends on the gap between the interest rate and the pure rate of time preference. In contrast, with imperfect annuities, individual consumption growth is negatively affected by the mortality rate, a result first demonstrated for the case with $\lambda=0$ by Yaari (1965, p. 143).

Equation 16 shows that scaled consumption of a newborn is proportional to scaled human wealth. Finally, Eq. 17 provides the definition of human wealth at birth. The first term on the right-hand side represents the present value of the time endowment during working life, using the growth-corrected annuity rate of interest for discounting. The

\footnotetext{
3 Another explanation for the overpricing of annuities is adverse selection (Finkelstein and Poterba 2002). That is, agents with a low mortality rate are more likely to buy annuities than agents with high mortality rates. However, because mortality is private information annuity firms "mis-price" annuities for low-mortality agents, thus creating a load factor. Abel (1986) and Heijdra and Reijnders (2009) study this adverse selection mechanism in a general equilibrium model featuring healthy and unhealthy people and with health status constituting private information. The unhealthy get a less than actuarially fair annuity rate whilst the healthy get a better than actuarially fair rate for part of life. An alternative source of imperfection may arise from the way that the annuity market is structured. Yaari (1965) assumes that there is a continuous spot market for annuities. In reality, however, investments in annuities are much lumpier. See Pissarides (1980) for an early analysis of this issue.
} 
second term on the right-hand side denotes the present value of the pension received during retirement. Finally, the third term on the right-hand side of Eq. 17 is just the present value of transfers arising from the annuity market imperfection.

The asset profiles accompanying the optimal consumption plans are given for a working-age individual $(0 \leq u<R)$ by:

$$
\begin{aligned}
\frac{A(v, v+u)}{w(v)} e^{-r u-\lambda M(u)}= & (1-\theta) \int_{0}^{u} E(s) e^{-(r-g) s-\lambda M(s)} d s \\
& +z \int_{0}^{u} e^{-(r-g) s-\lambda M(s)} d s \\
& -\frac{C(v, v)}{w(v)} \int_{0}^{u} e^{(\sigma-1)[r s+\lambda M(s)]-\sigma[\rho s+M(s)]} d s,
\end{aligned}
$$

and for a retiree $(R \leq u \leq D)$ by:

$$
\begin{aligned}
\frac{A(v, v+u)}{w(v)} e^{-r u-\lambda M(u)}= & \frac{C(v, v)}{w(v)} \int_{u}^{D} e^{(\sigma-1)[r s+\lambda M(s)]-\sigma[\rho s+M(s)]} d s \\
& -(\zeta+z) \int_{u}^{D} e^{-(r-g) s-\lambda M(s)} d s .
\end{aligned}
$$

\subsubsection{Aggregate Household Behaviour}

In this subsection we derive expressions for per-capita average consumption, labour supply, and saving. As is shown in Heijdra and Romp (2008, p. 94), with age-dependent mortality the demographic steady-state equilibrium has the following features:

$$
\begin{aligned}
1 & =\beta \int_{0}^{D} e^{-\pi s-M(s)} d s, \\
p(v, t) & \equiv \frac{P(v, t)}{P(t)} \equiv \beta e^{-\pi(t-v)-M(t-v)},
\end{aligned}
$$

where $\beta$ is the crude birth rate, $\pi$ is the growth rate of the population, $p(v, t)$ and $P(v, t)$ are, respectively, the relative and absolute size of cohort $v$ at time $t \geq v$, and $P(t)$ is the population size at time $t$. For a given birth rate, Eq. 21 determines the unique population growth rate consistent with the demographic steady state or vice versa. The average population-wide mortality rate, $\bar{\mu}$, follows residually from the fact that $\pi \equiv \beta-\bar{\mu}$. Equation 22 shows the two reasons why the relative size of a cohort falls over time, namely population growth and mortality. 
Using the cohort weights given in Eq. 22, we can define per-capita average values in general terms as:

$$
x(t) \equiv \int_{t-D}^{t} p(v, t) X(v, t) d v
$$

where $X(v, t)$ denotes the variable in question at the individual level, and $x(t)$ is the per capita average value of that same variable. Per capita aggregate household behaviour is summarized by the following expressions:

$$
\begin{aligned}
\frac{c(t)}{w(t)}=\beta \frac{C(v, v)}{w(v)} \int_{0}^{D} e^{\sigma[(r-\rho) s-(1-\lambda) M(s)]-(\pi+g) s-M(s)} d s, \\
n(t)=n \equiv \beta \int_{0}^{R} E(s) e^{-\pi s-M(s)} d s \\
\dot{a}(t)=(r-\pi) a(t)+w(t) n(t)-c(t) \\
+\left[\zeta \int_{R}^{D} \beta e^{-\pi s-M(s)} d s-\theta \int_{0}^{R} \beta E(s) e^{-\pi s-M(s)} d s\right] w(t) \\
+\left[(1-\lambda) \int_{0}^{D} \beta e^{-(g+\pi) s-M(s)} \mu(s) \frac{A(v, v+s)}{w(v)} d s-z\right] w(t) .
\end{aligned}
$$

Equation 24 relates the macroeconomic consumption-wage ratio to the optimally chosen scaled consumption level by newborns. Since this ratio is time-invariant, per capita consumption grows at the macroeconomic growth rate $g$. Equation 25 shows that aggregate per capita labour supply (in efficiency units) is a time-invariant constant. Finally, the growth rate in per capita financial assets is given in Eq. 26. This expression will be discussed in more detail below.

\subsection{Loose Ends}

We assume that the PAYG pension scheme is run on a balanced-budget basis. In view of Eqs. 11-12 and 22 this furnishes the following budget constraint:

$$
\zeta w(t) \int_{R}^{D} \beta e^{-\pi s-M(s)} d s=\theta w(t) \int_{0}^{R} \beta E(s) e^{-\pi s-M(s)} d s
$$

where the left-hand side stands for pension payments to retirees and the right-hand side represents pension contributions by workers. The mandatory retirement age $R$ is 
exogenous. Under the assumption of a DC system, $\theta$ is also exogenous and $\zeta$ adjusts to balance the budget. The opposite holds under a DB system. In view of Eq. 27, the PAYG system does not feature in the expression for aggregate asset accumulation, i.e. the second line of Eq. 26 is zero.

Excess profits of annuity firms can be written as follows:

$$
E P(v, t) \equiv(1-\lambda) \int_{t-D}^{t} p(v, t) \mu(t-v) A(v, t) d v
$$

The integral on the right-hand side represents per capita annuitized assets of all individuals that die in period $t$. This is the total revenue of annuity firms, of which only a fraction $\lambda$ is paid out to surviving annuitants. The remaining fraction, $1-\lambda$, is excess profit which is taxed away by the government and disbursed to all households in the form of lump-sum transfers, i.e. $E P(v, t)=T R(v, t)$. Using Eqs. 13 and 28 we find the implied expression for $z$ :

$$
z=(1-\lambda) \int_{0}^{D} \beta e^{-(g+\pi) u-M(u)} \mu(u) \frac{A(v, v+u)}{w(v)} d u
$$

Just as for the PAYG system, the redistribution of excess profits of annuity firms also debudget from the asset accumulation equation, i.e. the third line in Eq. 26 is also zero.

In the absence of government bonds, the capital market equilibrium condition is given by $A(t)=K(t)$ or, in per capita average terms, by:

$$
a(t)=k(t)
$$

where $k(t) \equiv K(t) / P(t)$ is the per capita stock of capital. From Eqs. 5 and 6 we easily find:

$$
\begin{aligned}
y(t) & =\Omega_{0} k(t), \\
w(t) n(t) & =(1-\varepsilon) y(t),
\end{aligned}
$$

where $y(t) \equiv Y(t) / P(t)$ is per capita output. From Eqs. 26, 27, 29 and 30 we can derive the expression for the macroeconomic growth rate:

$$
g \equiv \frac{\dot{k}(t)}{k(t)}=r-\pi+\left[n(t)-\frac{c(t)}{w(t)}\right] \frac{w(t)}{k(t)} .
$$

For convenience, the key equations comprising the general equilibrium model have been gathered in Table 1. Equations (T1.1)-(T1.2), (T1.3a)-(T1.3b), (T1.4)-(T1.6), (T1.8)-(T1.9) restate, respectively, Eqs. 16-17, 19-20, 24, 25, 27, 29, and 33. Equation (T1.7) is obtained by combining Eqs. 31 and 32 and noting Eq. 25. 
Table 1 The model

(a) Microeconomic relationships:

$$
\begin{gathered}
\frac{C(v, v)}{w(v)}=\frac{1}{\int_{0}^{D} e^{-(1-\sigma)[r s+\lambda M(s)]-\sigma[\rho s+M(s)]} d s} \cdot \frac{H(v, v)}{w(v)} \\
\frac{H(v, v)}{w(v)}=(1-\theta) \int_{0}^{R} E(s) e^{-(r-g) s-\lambda M(s)} d s+\zeta \int_{R}^{D} e^{-(r-g) s-\lambda M(s)} d s \\
+z \int_{0}^{D} e^{-(r-g) s-\lambda M(s)} d s \\
\frac{A(v, v+u)}{w(v)} e^{-r u-\lambda M(u)}=(1-\theta) \int_{0}^{u} E(s) e^{-(r-g) s-\lambda M(s)} d s+z \int_{0}^{u} e^{-(r-g) s-\lambda M(s)} d s \\
\quad-\frac{C(v, v)}{w(v)} \int_{0}^{u} e^{-(1-\sigma)[r s+\lambda M(s)]-\sigma[\rho s+M(s)]} d s \\
=\frac{C(v, v)}{w(v)} \int_{u}^{D} e^{-(1-\sigma)[r s+\lambda M(s)]-\sigma[\rho s+M(s)]} d s \\
-(\zeta+z) \int_{u}^{D} e^{-(r-g) s-\lambda M(s)} d s
\end{gathered}
$$

(b) Macroeconomic relationships:

$$
\begin{aligned}
& \zeta=\theta \cdot \frac{\int_{0}^{R} \beta E(s) e^{-\pi s-M(s)} d s}{\int_{R}^{D} \beta e^{-\pi s-M(s)} d s} \\
& z=(1-\lambda) \int_{0}^{D} \beta e^{-(g+\pi) u-M(u)} \mu(u) \frac{A(v, v+u)}{w(v)} d u \\
& g \equiv \frac{k(t)}{k(t)}=r-\pi+\left[n-\frac{c(t)}{w(t)}\right] \frac{w(t)}{k(t)} \\
& \frac{w(t) n}{k(t)}=(1-\varepsilon) \Omega_{0} \\
& n=\beta \int_{0}^{R} E(s) e^{-\pi s-M(s)} d s \\
& \frac{c(t)}{w(t)}=\beta \frac{C(v, v)}{w(v)} \int_{0}^{D} e^{\sigma[(r-\rho) s-(1-\lambda) M(s)]-(\pi+g) s-M(s)} d s
\end{aligned}
$$

Definitions: Endogenous are $C(v, v) / w(v), H(v, v) / w(v), A(v, v+u) / w(v), \zeta, z, g, n, w(t) / k(t)$, and $c(t) / w(t)$. Parameters: $R$ retirement age, $\theta$ pension contribution rate, birth rate $\beta$, aggregate mortality rate $\bar{\mu}$, population growth rate $\pi \equiv \beta-\bar{\mu}$, imperfection annuities $\lambda$, rate of time preference $\rho$, capital coefficient in the technology $\varepsilon$, scale factor in the technology $\Omega_{0}$. The interest rate is $r \equiv \varepsilon \Omega_{0}-\delta$, where $\delta$ is the depreciation rate of capital

The model features a two-way interaction between the microeconomic decisions and the macroeconomic outcomes. Indeed, conditional on the macroeconomic variables, equations (T1.1)-(T1.3) determine scaled newborn consumption and human wealth, $C(v, v) / w(v)$ and $H(v, v) / w(v)$ as well as the age profile of scaled assets $A(v, v+u) / w(v)$. Conditional on these microeconomic variables, equations (T1.4)(T1.9) determine equilibrium pension payments and transfers, $\zeta$ and $z$, the macroeconomic growth rate, $g$, the overall wage-capital ratio, $w(t) / k(t)$, aggregate labour supply, $n$, and the $c(t) / w(t)$ ratio.

\subsection{Adding Empirical Content}

An important virtue of the analytical approach adopted here is that it allows one to pinpoint the various places where life-cycle elements affect individual choices and aggregate outcomes. The model contains three main mechanisms giving rise to lifecycle effects. First, the mortality process is age-dependent, i.e. the instantaneous and cumulative hazard rates $(\mu(u)$ and $M(u))$ both depend on age. Second, labour productivity $(E(u))$ depends on the worker's age. Third, the pension system and mandatory retirement age differentiates workers from retirees. In the remainder of this section 
we add empirical content to the model by plausibly calibrating the various life-cycle mechanisms.

To capture the demographic process we use the model suggested by Boucekkine et al. (2002), which incorporates a finite maximum age. The surviving fraction up to age $u$ (from the perspective of birth) is given by:

$$
e^{-M(u)} \equiv \frac{\eta_{0}-e^{\eta_{1} u}}{\eta_{0}-1},
$$

with $\eta_{0}>1$ and $\eta_{1}>0$. For this demographic process, $D=\left(1 / \eta_{1}\right) \ln \eta_{0}$ is the maximum attainable age, whilst the instantaneous mortality rate at age $u$ is given by:

$$
\mu(u) \equiv \frac{\eta_{1} e^{\eta_{1} u}}{\eta_{0}-e^{\eta_{1} u}}
$$

The mortality rate is increasing in age and becomes infinite at $u=D$.

In Heijdra and Mierau (2010) we use data from age 18 onward for the Dutch cohort that was born in 1960. We denote the actual surviving fraction up until model age $u_{i}$ by $S_{i}$, and estimate the parameters of the parametric distribution function by means of non-linear least squares. The model to be estimated is thus:

$$
S_{i}=1-\Phi\left(u_{i}\right)+\varepsilon_{i}=d\left(u_{i} \leq D\right) \cdot \frac{\eta_{0}-e^{\eta_{1} u_{i}}}{\eta_{0}-1}+\varepsilon_{i},
$$

where $d\left(u_{i} \leq D\right)=1$ for $u_{i} \leq D$, and $d\left(u_{i} \leq D\right)=0$ for $u_{i}>D$, and $\varepsilon_{i}$ is the stochastic error term. We find the following estimates (with $t$ statistics in brackets): $\hat{\eta}_{0}=122.643(11.14), \hat{\eta}_{1}=0.0680(48.51)$. The standard error of the regression is $\hat{\sigma}=0.02241$, and the implied estimate for $D$ is 70.75 model years (i.e. the maximum age in biological years is 88.75 ). Figure 1a depicts the actual and fitted survival rates with, respectively, solid and dashed lines. Up to age 69 , the model fits the data rather well. For higher ages the fit deteriorates as the estimated model fails to capture the fact that some people are expected to live very long lives in reality. Figure $1 \mathrm{~b}$ depicts the implieds instantaneous mortality rate. Mortality is very low and virtually constant up to model age $u=50$ (corresponding with biological age 68) but rises at an increasing rate thereafter. Finally, Fig. 1c shows the implied relative cohort sizes.

Several studies have argued that labour productivity is hump-shaped-see for example Hansen (1993) and Ríos-Rull (1996). ${ }^{4}$ An analytically convenient age profile for productivity involves exponential terms:

$$
E(u)=\alpha_{0} e^{-\zeta_{0} u}-\alpha_{1} e^{-\zeta_{1} u}
$$

where $E(u)$ is labour productivity of a $u$-year old worker, and we assume that $\alpha_{0}>$ $\alpha_{1}>0, \zeta_{1}>\zeta_{0}>0$, and $\alpha_{1} \zeta_{1}>\alpha_{0} \zeta_{0}$. We easily find that $E(u) \geq 0, E(0)=$

\footnotetext{
4 The relationship between age and worker productivity is studied in a number of recent papers by Lallemand and Rycx (2009) and van Ours (2009).
} 
(a) mortality process

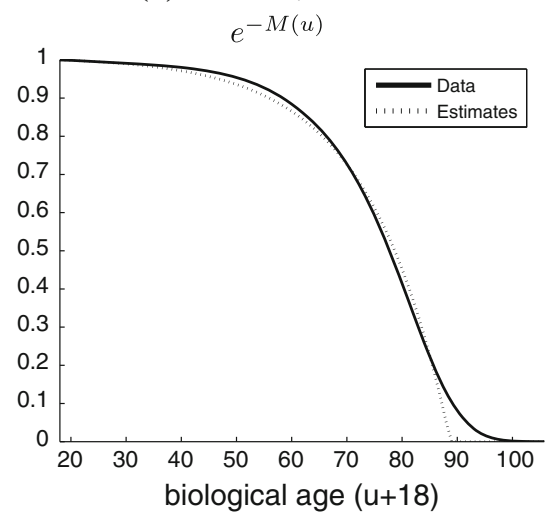

(c) relative cohort size

$\beta e^{-\pi u-M(u)}$

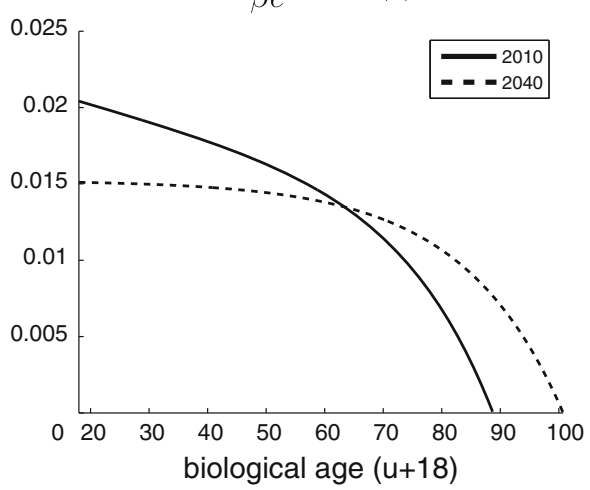

(b) instantaneous mortality rate

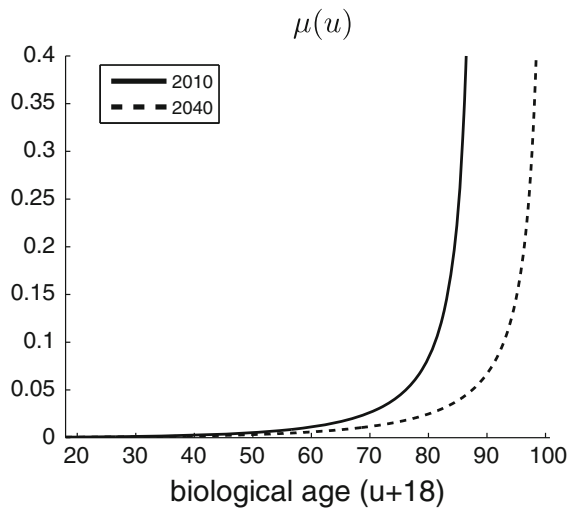

(d) efficiency profile

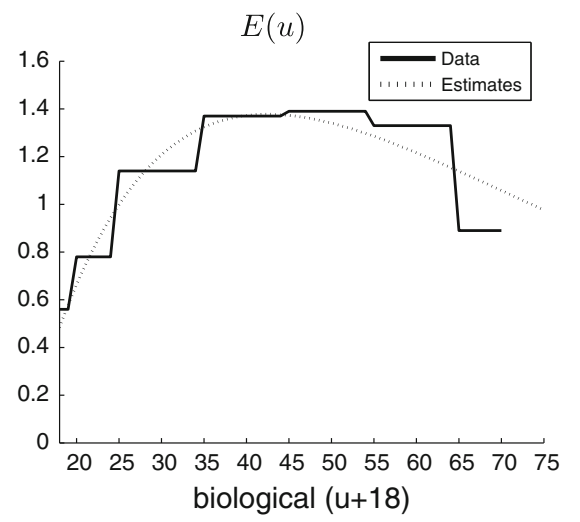

Fig. 1 Life-cycle features. Notes: $u$ is the agent's age, $\beta$ is the crude birth rate, $\pi$ is the population growth rate, $M(u)$ is the cumulative mortality factor, $\mu(u)$ is the instantaneous mortality rate, and $E(u)$ is labour productivity at age $u$. The maximum attainable age estimated with Dutch data is $D=70.75$

$\alpha_{0}-\alpha_{1}>0, \lim _{u \rightarrow \infty} E(u)=0, E^{\prime}(u)>0$ (for $0 \leq u<\bar{u}$ ) and $E^{\prime}(u)<0$ (for $u \geq \bar{u}$ ) where the peak occurs at age $\bar{u}$ :

$$
\bar{u}=\frac{1}{\zeta_{1}-\zeta_{0}} \ln \left(\frac{\alpha_{1} \zeta_{1}}{\alpha_{0} \zeta_{0}}\right) .
$$

Labour productivity is non-negative throughout life, starts out positive, is rising during the first life phase, and declines thereafter. Using cross-section efficiency data for male workers aged between 18 and 70 from Hansen (1993, p. 74) we find the solid pattern in Fig. 1d. We interpolate these data by fitting equation (Eq. 37) using non-linear least squares. We find the following estimates ( $t$ statistics in brackets): $\alpha_{0}=4.494$ (fixed), $\hat{\alpha}_{1}=4.010$ (71.04), $\hat{\zeta}_{0}=0.0231(24.20)$, and $\hat{\zeta}_{1}=0.050(17.81)$. The fitted productivity profile is illustrated with dashed lines in Fig. 1d. 
Finally, for the third life-cycle feature - the PAYG pension system-we assume that the mandatory retirement age is set at $R=47$ (corresponding with 65 in biological years) and that the pension contribution rate is seven percent of wage income, i.e. $\theta=0.07$ which roughly corresponds with the Dutch pension system. The implied pension benefit is determined in general equilibrium.

The remainder of the core model is parameterized as follows. We postulate the existence of perfect annuities (PA, with $\lambda=1$ ). We assume that the rate of population growth is half of one percent per annum $(\pi=0.005)$. For the estimated demographic process, Eq. 21 yields a steady-state birth rate equal to $\beta=0.0204$. Since $\bar{\mu} \equiv \beta-\pi$, this implies that the average mortality rate is $\bar{\mu}=0.0154$. The old-age dependency ratio equals $22.92 \%$. We model an economy with a steady-state capital-output ratio of 2.5 , which is obtained by setting $\Omega_{0}=0.4$. The interest rate is five percent per annum $(r=0.05)$, the capital depreciation rate is seven percent per annum $(\delta=0.07)$, and the efficiency parameter of capital is set at $\varepsilon=0.3$. The steady-state growth rate is set equal to two percent per annum $(g=0.02)$. For the intertemporal substitution elasticity we use $\sigma=0.7$, a value consistent with the estimates reported by Attanasio and Weber (1995). The rate of pure time preference is used as a calibration parameter, yielding a value of $\rho=0.0112$.

Table 2(a) reports the main features of the initial steady-state growth path. With perfect annuities, there are no excess profits of annuity firms and thus no transfers, i.e. $z=0$ in Table 2(a). Note also that at retirement age $R$ a vintage- $v$ agent receives $\zeta w(v+R)$ in the form of a pension whereas the last-received wage for this agent equals $E(R) w(v+R)$. The replacement rate is thus equal to $\zeta / E(R)=0.3189$.

We visualize the life-cycle profiles for a number a key variables in Fig. 2. The solid lines are associated with the core model featuring perfect annuities. For ease of interpretation, the horizontal axes report biological age, $u+18$. Figure 2 a shows that with perfect longevity insurance consumption rises monotonically over the life cycle. This counterfactual result follows readily from Eq. 18 which for $\lambda=1$ simplifies to $\dot{C}(v, \tau) / C(v, \tau)=\sigma(r-\rho)$. Figure $2 \mathrm{~b}$ depicts the age profile of scaled financial assets. At first the agent is a net borrower, i.e. a buyer of life-insured loans. Thereafter annuity purchases are positive and the profile of assets is bellshaped. In the absence of a bequest motive, the agent plans to run out of financial assets at the maximum age $D$. Figure 2c shows the profile of scaled wages over the life cycle. Despite the fact that individual labour productivity itself is bellshaped (see Fig. 1d), wages increase monotonically as a result of ongoing economic growth. Finally, in Fig. 2d we illustrate the profile for scaled pension receipts. During the working career these payments are negative and proportional to scaled wages, whilst they are positive and proportional to the economy-wide wage rate during retirement.

Despite its simplicity the model captures some of the main stylized facts regarding life cycles. Indeed, as is documented by inter alia Huggett (1996), in real life financial assets typically display a hump-shaped profile and remain non-negative in old age. The model also features a realistic age profile for labour supply. Indeed, as is pointed out by McGrattan and Rogerson (2004) (for the United States), labour supply is constant and age-invariant for most of working life and tapers off rapidly near the retirement age. 
Table 2 Quantitative effects

\begin{tabular}{|c|c|c|c|c|c|c|c|c|}
\hline \multirow[t]{3}{*}{ Case } & \multicolumn{2}{|c|}{ Core cases } & \multicolumn{2}{|l|}{$\mathrm{DC}$} & \multicolumn{2}{|l|}{ DB } & \multicolumn{2}{|l|}{ RA } \\
\hline & (a) & (b) & (c) & (d) & (e) & (f) & (g) & (h) \\
\hline & PA & IA & PA & IA & PA & IA & PA & IA \\
\hline$\frac{C(v, v)}{w(v)}$ & 0.8534 & 0.8609 & 1.0784 & 1.0785 & 0.9078 & 0.9053 & 0.9329 & 0.9369 \\
\hline$\frac{H(v, v)}{w(v)}$ & 26.5646 & 27.0207 & 36.0229 & 36.2942 & 30.3246 & 30.4653 & 31.1617 & 31.5282 \\
\hline$g(\%)$ & 2.00 & 1.91 & 3.36 & 3.27 & 2.79 & 2.68 & 2.39 & 2.30 \\
\hline$n$ & 0.9675 & 0.9675 & 0.8212 & 0.8212 & 0.8212 & 0.8212 & 0.9589 & 0.9589 \\
\hline$\frac{w(t)}{k(t)}$ & 0.2894 & 0.2894 & 0.3410 & 0.3410 & 0.3410 & 0.3410 & 0.2920 & 0.2920 \\
\hline$\frac{c(t)}{w(t)}$ & 1.0538 & 1.0570 & 0.8692 & 0.8720 & 0.8861 & 0.8893 & 1.0482 & 1.0514 \\
\hline$\zeta$ & 0.3632 & 0.3632 & 0.1824 & 0.1824 & 0.3632 & 0.3632 & 0.3632 & 0.3632 \\
\hline$z$ & & 0.0200 & & 0.0142 & & 0.0131 & & 0.0185 \\
\hline$\theta$ & & & & & 0.1394 & 0.1394 & & \\
\hline$R+18$ & & & & & & & 75.3 & 75.3 \\
\hline
\end{tabular}

Notes: PA stands for perfect annuities $(\lambda=1)$ and IA denotes imperfect annuities $(\lambda=0.7)$. Column (a) is the core model. Column (b) shows the effects of the annuity market imperfection in the core model. Columns (c)-(d) show the effects of a demographic shock under a DC pension system. Columns (e)-(f) show the effects under a DB system. In this scenario the tax rate $\theta$ adjusts to keep $\zeta$ at its pre-shock level. Columns (g)-(h) show the effects under a retirement age (RA) scenario in which $\theta$ and $\zeta$ are kept at their pre-shock levels and $R$ is adjusted

In contrast, the model does not provide a realistic profile for consumption. In the core model the age profile for consumption is monotonically increasing, whereas it is hump-shaped in reality. See for example, Gourinchas and Parker (2002) and Fernandez-Villaverde and Krueger (2007) for evidence on the US, and Alessie and de Alessie and de Ree (2009) for a recent study using Dutch data.

Referring to the consumption Euler equation (Eq. 18) it is clear that an annuity market imperfection can account for a hump-shaped pattern of consumption. Indeed, with $0<\lambda<1$ it follows from Eq. 18 and Fig. 1b that consumption growth is positive during the early phase of life because the mortality rate is low, i.e. $r-\rho>$ $(1-\lambda) \mu(u)$. Toward the end of life, however, the instantaneous death probability rises sharply, the inequality is reversed, and the optimal consumption profile is downward sloping. 5

In order to quantify and visualize the effects of an annuity market imperfection we recompute the general equilibrium of the model using the structural parameters mentioned above but setting $\lambda=0.7$. This degree of annuity market imperfection is in the order of magnitude found by Friedman and Warshawsky (1988, p. 59).

\footnotetext{
5 Consumption peaks at age $\hat{u}$, which is defined implicitly by $\mu(\hat{u})=(r-\rho) /(1-\lambda)$. Since $\mu^{\prime}(u)>0$ we find that $d \hat{\mu} / d \lambda>0$ and $d \hat{\mu} / d(r-\rho)>0$. Hence, the smaller is $\lambda$ or $r-\rho$, the lower is the age at which consumption peaks. Note that whereas $\lambda$ can help determine the location of the kink, the intertemporal substitution elasticity $\sigma$ cannot do so.
} 
(a) scaled consumption

$$
\frac{C(v, v+u)}{w(v)}
$$

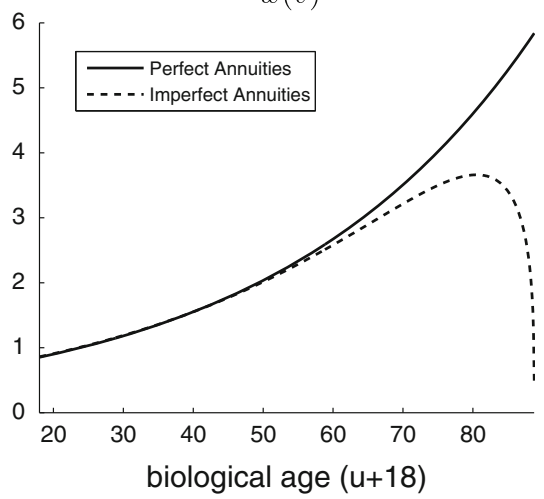

(c) scaled wage rate

$$
\frac{w(v, v+u)}{w(v)}
$$

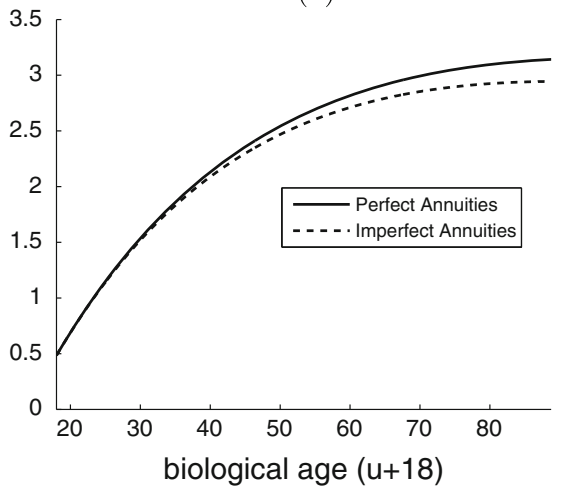

(b) scaled financial assets

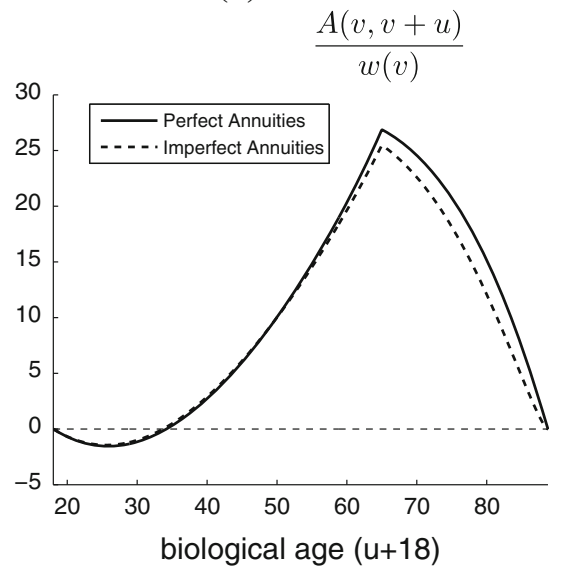

(d) scaled pension receipts

$$
\frac{P R(v, v+u)}{w(v)}
$$

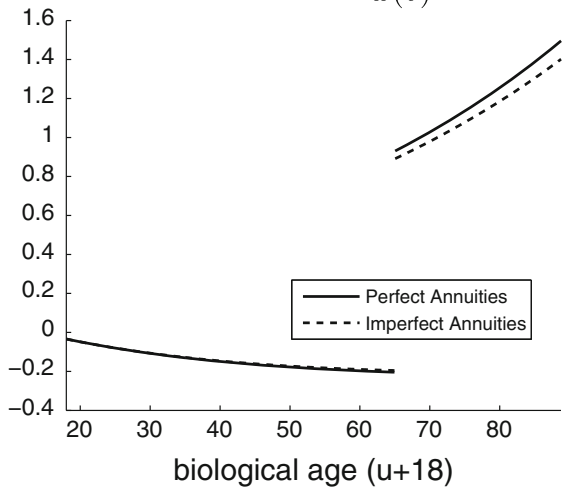

Fig. 2 Life-cycle profiles and the role of annuity imperfections

Table 2(b) reports the quantitative implications of the annuity market imperfection. Two features stand out. First, in the presence of imperfect annuities excess profits of annuity firms are positive and transfers are thus strictly positive $(z=0.0200)$. Each surviving agent thus receives about two percent of the macroeconomic wage rate in each period in the form of transfers. Second, the macroeconomic growth rate falls by nine basis points, from 2 percent to 1.91 percent per annum.

The ultimate effect on newborn consumption of the change in $\lambda$ depends on the interplay between the human wealth effect and the propensity effect. Recall from (T1.1)-(T1.2) that $C(v, v)=\Delta \cdot H(v, v)$ where the propensity to consume is defined as:

$$
\Delta \equiv \frac{1}{\int_{0}^{D} e^{-(1-\sigma)[r s+\lambda M(s)]-\sigma[\rho s+M(s)]} d s} .
$$


It is easy to show that with $0<\sigma<1$, the propensity to consume out of human wealth falls as a result of the reduction in $\lambda$ :

$$
\frac{d \Delta}{d \lambda}=(1-\sigma) \Delta^{2} \cdot \int_{0}^{D} M(s) e^{-(1-\sigma)[r s+\lambda M(s)]-\sigma[\rho s+M(s)]} d s>0 .
$$

The partial derivative of scaled human wealth with respect to $\lambda$ is given by:

$$
\begin{aligned}
\frac{\partial}{\partial \lambda} \frac{H(v, v)}{w(v)}= & -(1-\theta) \int_{0}^{R} M(s) E(s) e^{-(r-g) s-\lambda M(s)} d s \\
& -\zeta \int_{R}^{D} M(s) e^{-(r-g) s-\lambda M(s)} d s \\
& -z \int_{0}^{D} M(s) e^{-(r-g) s-\lambda M(s)} d s<0 .
\end{aligned}
$$

A decrease in $\lambda$ results in a reduction in the annuity rate of interest at all age levels and thus an increase in human wealth due to less severe discounting of non-asset income streams. Human wealth is also affected by two of the macroeconomic variables, namely transfers $z$ and the growth rate $g$ (note that $n, \zeta$, and $w(t) / k(t)$ are not affected by $\lambda$ ). Scaled human wealth is boosted as a result of the transfers:

$$
\frac{\partial}{\partial z} \frac{H(v, v)}{w(v)}=\int_{0}^{D} e^{-(r-g) s-\lambda M(s)} d s>0
$$

but it is reduced by the decrease in the growth rate:

$$
\begin{aligned}
\frac{\partial}{\partial g} \frac{H(v, v)}{w(v)}= & (1-\theta) \int_{0}^{R} s E(s) e^{-(r-g) s-\lambda M(s)} d s+\zeta \int_{R}^{D} s e^{-(r-g) s-\lambda M(s)} d s \\
& +z \int_{0}^{D} s e^{-(r-g) s-\lambda M(s)} d s>0 .
\end{aligned}
$$

The results in Table 2(b) confirm that for our parameterization scaled consumption and human wealth both increase, i.e. the effects in Eqs. 41 and 42 dominate the combined propensity effect (Eq. 40) and growth effect (Eq. 43).

In Fig. 2 the dashed lines depict the life-cycle profiles associated with the model featuring imperfect annuities. Scaled consumption is hump-shaped but peaks at a rather 
high age. ${ }^{6}$ The profiles for scaled financial assets, wages, and pension payments are all very similar to the ones for the core model. ${ }^{7}$

\section{Ageing: The Big Picture}

In this section we put our model to work on the big policy issue of demographic change. Population ageing remains one of the key issues in economic policy in the Netherlands. During the 2010 Dutch parliamentary election campaign numerous parties went so far as to call future policy on pensions and the retirement age a breaking point for the post-electoral coalition scramble. In this section we look at the big picture and study the effect of ageing and demographic change on the steady-state rate of economic growth of a country. 8

We start our analysis with some stylized facts for the Netherlands. ${ }^{9}$ In the period 2005-2010 the crude birth rate is about $\beta=1.13 \%$ per annum whereas for 20352040 it is projected to change to $\beta=1.05 \%$ per annum. The population growth rates are, respectively, $\pi=0.41 \%$ per annum for $2005-2010$ and $\pi=-0.01 \%$ per annum 2035-2040. Finally, the old-age dependency ratio is, respectively $23 \%$ in 2010 and $46 \%$ in 2040. We wish to simulate our model using a demographic shock which captures the salient features of these stylized facts. Since we restrict attention to steady-state comparisons in this paper, we make the strong assumption that the country finds itself in a demographic steady state both at present and in 2040.

\subsection{A Demographic Shock}

The demographic shock that we study is as follows. First, we assume that the population growth rate changes from $\pi_{0}=0.5 \%$ to $\pi_{1}=0 \%$ per annum. Second, we use our estimated demographic process (Eq. 34) but change the $\eta_{1}$ parameter in such a way that an old-age dependency ratio of $46 \%$ is obtained. Writing $e^{-M_{i}(u)} \equiv$ $\left(\hat{\eta}_{0}-e^{\eta_{1, i} u}\right) /\left(\hat{\eta}_{0}-1\right)$ the old-age dependency ratio can be written as:

$$
d r\left(\pi_{i}, \eta_{1, i}\right) \equiv \frac{\int_{47}^{D_{i}} e^{-\pi_{i} s-M_{i}(s)} d s}{\int_{0}^{47} e^{-\pi_{i} s-M_{i} s} d s},
$$

\footnotetext{
6 Bütler (2001) and Hansen and İmrohoroğlu (2008) also find that the hump occurs too late in life. Alessie and de Ree (2009, p. 113) decompose Dutch consumption into durables and non-durables. They find that non-durable consumption peaks at age 45 whereas durable consumption reaches its maximum at about age 41 .

7 We study the consequences of annuitization for economic growth and individual welfare in Heijdra and Mierau (2009, 2010) and Heijdra et al. (2010). The latter paper demonstrates the existence of a "tragedy of annuitization". Although full annuitization of assets is privately optimal it may not be socially beneficial due to adverse general equilibrium repercussions.

${ }^{8}$ For an accessible survey of the literature on the topic of population ageing and economic growth, see Bloom et al. (2008). Recent contributions using the endogenous growth framework include Fougère and Mérette (1999), Futagami and Nakajima (2001), Heijdra and Romp (2006) and Prettner (2009).

9 These figures are taken from United Nations, World Population Prospects: The 2008 Revision Population Data Base,http://esa.un.org/unpp. We use data for the medium variant.
} 
where $D_{i} \equiv\left(1 / \eta_{1, i}\right) \ln \eta_{0}$. Using this expression we find that $\eta_{1}$ changes from $\eta_{1,0}=$ $\hat{\eta}_{1}=0.0680$ to $\eta_{1,1}=0.0581$. The associated values for the crude birth rate are by imposing the suitably modified demographic steady-state condition (Eq. 21). We find that $\beta$ changes in the model from $\beta_{0}=0.0204$ to $\beta_{1}=0.0151$. Figure $1 \mathrm{~b}$ shows that the new instantaneous mortality profile shifts to the right. Figure $1 \mathrm{c}$ illustrates the change in the population composition. In the new steady state, the population distribution features less mass at lower ages and more at higher ages, i.e. the population pyramid becomes narrower and higher.

The effect on the economic growth rate of the demographic shock depends critically on the type of pension system. We consider three scenarios. In the first scenario the pension system is DC, the contribution rate and retirement age are kept constant $\left(\theta_{0}=0.07\right.$ and $\left.R_{0}=47\right)$, pension payments to the elderly are reduced to balance the budget of the PAYG system. Columns (c)-(d) in Table 2 report the results for the two cases with perfect (PA) and imperfect annuities (PA). Since the effects are qualitatively the same for PA and IA, we restrict attention to the latter case. Comparing columns (b) and (d) several features stand out. First, the ageing shock has a large effect on the supply of (efficiency units of) labour, i.e. $n$ falls by more than fifteen percent. This is an obvious consequence of the fact that the population proportion of working-age persons declines (see Fig. 1d). Second, the pension payments to retirees are almost halved. Third, notwithstanding the decrease in pensions, scaled consumption and human wealth at birth both increase dramatically. More people expect to survive into retirement and, once retired, the period of retirement is also increased. Fourth, the macroeconomic growth rate increases dramatically, from 1.91 to $3.27 \%$ per annum. The intuition behind this strong growth effect can be explained with the aid of Fig. 3. The solid lines represents the core case of Table 2(b) and the dashed lines illustrate the results from Table 2(d). Following the demographic shock scaled consumption is uniformly higher and peaks at a later age. Scaled financial assets are somewhat lower during youth but much higher thereafter. As Fig. $3 \mathrm{~b}$ shows there is a huge savings response which explains the large increase in the macroeconomic growth rate. In conclusion, of the main growth channels identified by Bloom et al. (2008, p. 2), labour supply falls (and thus retards growth) but the capital accumulation effect is so strong as to lead to a strong positive effect of longevity on economic growth.

In the second scenario the pension system is $\mathrm{DB}$, the pension payments and retirement age are kept constant $\left(\zeta_{0}=0.3632\right.$ and $\left.R_{0}=47\right)$, and pension contributions by the young are increased to balance the budget of the PAYG system. Columns (e)-(f) in Table 2 give the results for this case. Comparing columns (b), (d) and (f) the following features stand out. First, the contribution rate increased is quite substantial, it almost doubles from $\theta_{0}=0.07$ to $\theta_{1}=0.1394$. Second, though scaled consumption, scaled human wealth, and the economic growth rate are higher than in the base case, they are lower than under the DC scenario. As Fig. 3 shows, the capital accumulation effect of the longevity shock is substantially dampened under a DB system. Intuitively, by taking from the young and giving to the old the PAYG system redistributes from net savers to net dissavers.

Finally, in the third scenario both $\theta$ and $\zeta$ are kept at their pre-shock levels and the retirement age is increased to balance the budget of the PAYG system. Columns (g)-(h) in Table 2 give the results for this case. Comparing columns (b), (d), (f), and 
(a) scaled consumption

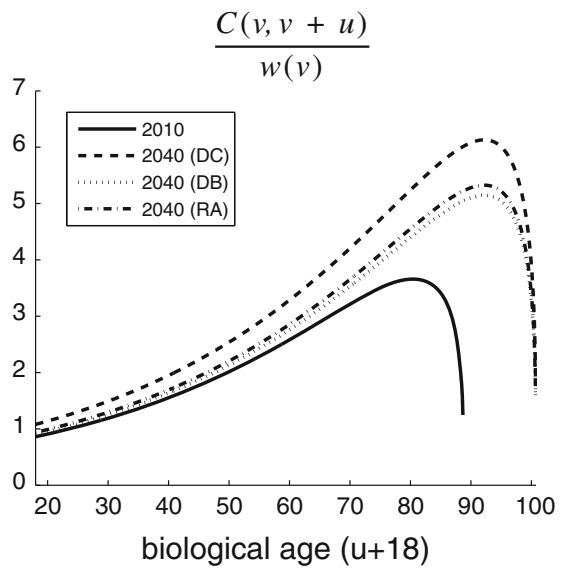

(b) scaled financial assets

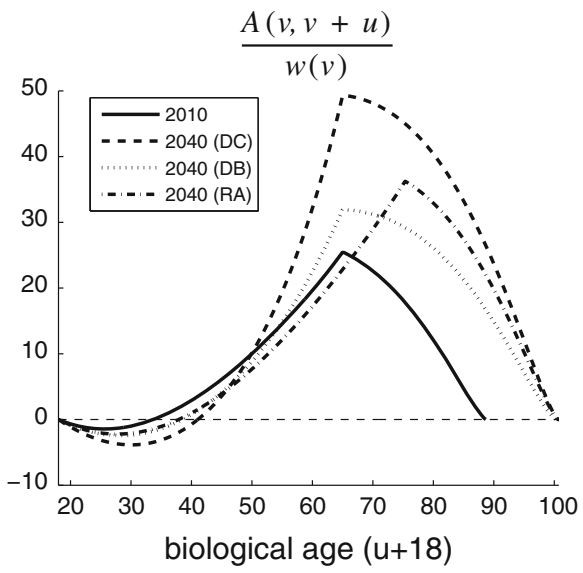

Fig. 3 Life-cycle profiles before and after the demographic shock

(h) the following features stand out. First, under the retirement age (RA) scenario the longevity shock necessitates an increase in the biological retirement age 65 to 75.3 years. i.e. the value of $R$ restoring budget balance changes from $R_{0}=47$ to $R_{1}=57.3$. Second, compared to the DB and DC cases, labour supply increases strongly in the RA scenario. Third, the economic growth rate, though still higher than in the base case, is slightly lower that under DB and much lower than under DC. The intuition behind this result is clear from Fig. $3 \mathrm{~b}$ which shows that the savings response following the longevity shock is lower than either DB or DC.

\subsection{Robustness}

The clear message emerging from the discussion so far is that the type of pension system in place has a quantitatively large influence on the link between longevity and macroeconomic growth. Indeed, the same longevity shock can either lead to a huge increase in growth (under DC) or only a modest increase (under RA). But how robust are these conclusions? As is pointed out by Bloom et al. (2008, p. 3), "population data are not sacrosanct" and UN predictions are revised substantially over time. In short, our stylized demographic facts may be more like "factoids". ${ }^{10}$

We study the robustness issue in Table 3 . We restrict attention to the case with imperfect annuities, and column (a) in the table represents the base case. It coincides with the pre-shock steady state reported in Table 2(b). Columns (b)-(c) in Table 3 report the results under the DC scenario for alternative demographic shocks. In contrast, columns (d)-(e) show how a much more broadly defined PAYG system reacts to the original demographic shock under DC, DB, and RA.

\footnotetext{
10 De Waegenaere et al. (2010) provide a survey of the recent literature on longevity risk (i.e. the risk that mortality predictions turn out to be wrong). In accordance with Bloom et al. (2008) they show that estimates on future mortality rates differ substantially and depend on a plethora of uncertain factors.
} 
Table 3 Alternative scenarios

\begin{tabular}{|c|c|c|c|c|c|c|c|}
\hline & \multicolumn{3}{|c|}{ Initial PAYG system } & \multicolumn{4}{|c|}{ Large PAYG system } \\
\hline & (a) & $\begin{array}{l}\text { (b) } \\
\text { DC }\end{array}$ & $\begin{array}{l}\text { (c) } \\
\text { DC }\end{array}$ & (d) & $\begin{array}{l}\text { (e) } \\
\text { DC }\end{array}$ & $\begin{array}{l}\text { (f) } \\
\text { DB }\end{array}$ & $\begin{array}{l}(\mathrm{g}) \\
\text { RA }\end{array}$ \\
\hline$\frac{C(v, v)}{w(v)}$ & 0.8609 & 0.9268 & 1.0971 & 0.7047 & 0.8818 & 0.6109 & 0.7678 \\
\hline$\frac{H(v, v)}{w(v)}$ & 27.0207 & 29.4510 & 38.0243 & 22.1187 & 29.6744 & 20.5594 & 25.8384 \\
\hline $\begin{array}{l}g(\%) \\
n\end{array}$ & $\begin{array}{l}1.91 \\
0.9675\end{array}$ & $\begin{array}{l}2.33 \\
0.9217\end{array}$ & $\begin{array}{l}3.43 \\
0.8155\end{array}$ & $\begin{array}{l}1.19 \\
0.9675\end{array}$ & $\begin{array}{l}2.59 \\
0.8212\end{array}$ & $\begin{array}{l}1.51 \\
0.8212\end{array}$ & $\begin{array}{l}1.71 \\
0.9589\end{array}$ \\
\hline$\frac{w(t)}{k(t)}$ & 0.2894 & 0.3038 & 0.3434 & 0.2894 & 0.3410 & 0.3410 & 0.2920 \\
\hline $\begin{array}{l}k(t) \\
\frac{c(t)}{w(t)}\end{array}$ & 1.0570 & 1.0094 & 0.8465 & 1.0817 & 0.8918 & 0.9236 & 1.0715 \\
\hline $\begin{array}{l}\zeta \\
z \\
\theta\end{array}$ & $\begin{array}{l}0.3632 \\
0.0200\end{array}$ & $\begin{array}{l}0.2796 \\
0.0200\end{array}$ & $\begin{array}{l}0.1812 \\
0.0111\end{array}$ & $\begin{array}{l}0.7783 \\
0.0174\end{array}$ & $\begin{array}{l}0.3910 \\
0.0130\end{array}$ & $\begin{array}{l}0.7783 \\
0.0120 \\
0.2986\end{array}$ & $\begin{array}{l}0.7783 \\
0.0148\end{array}$ \\
\hline$R+18$ & & & & & & & 75.3 \\
\hline
\end{tabular}

Notes: Column (a) is the core model with imperfect annuities (column (b) in Table 2). Column (b) dependency ratio in 2040 equal to $30 \%$ instead of $46 \%$. Column (c) population growth rate in 2040 equal to $0.5 \%$ instead of $0 \%$ per annum. Column (d) bigger PAYG system $(\theta=0.15)$. Columns (e)-(f) show the effects of the original demographic shock for the large PAYG system under DC and DB. Column (g) leaves $\theta$ and $\zeta$ unchanged and features a higher retirement age

In column (b) we assume that the old-age dependency ratio is $30 \%$ rather than $46 \%$ in 2040. As in the original shock we continue to assume that $\pi_{1}=0 \%$ per annum. By using Eq. 44 we obtain new values for the demographic parameters, i.e. $\eta_{1,1}=0.0662$ and $\beta_{1}=\bar{\mu}_{1}=0.0172$. The alternative demographic shock causes a small increase in the economic growth rate. Whereas the original demographic shock caused growth to increase from 1.91 to $3.27 \%$ per annum (see Table 2, columns (b) and (d)), the alternative one only raises the growth rate to $2.33 \%$ per annum. The alternative ageing shock is relatively small, and pensions are reduced much less drastically than under the original demographic shock. The private savings response is quite small as a result.

In column (c) we keep the dependency ratio at $46 \%$ but assume that the population growth rate is $0.5 \%$ rather than $0 \%$ per annum in 2040 . Under this assumption the demographic parameters are equal to $\eta_{1,1}=0.0540, \beta_{1}=0.0168$, and $\bar{\mu}_{1}=0.0118$. This type of demographic shock produces a huge increase in the macroeconomic growth rate. The intuition is the same as before-see the discussion relating to Table 2(d) above. The large growth effect is all the more surprising in view of the growth equation (T1.6) which directly features $-\pi$ on the right-hand side. So even though the demographic shock itself retards growth by $0.5 \%$ per annum, the huge private savings response more than compensates for this effect.

In conclusion, the two alternative demographic shocks give rise to qualitatively the same predictions as we obtained for the original shock. Under a DC system economic growth is boosted because the labour supply effect is strongly dominated by the capital accumulation effect. 
As a final robustness check we investigate whether the size of the PAYG system influences the relationship between longevity and economic growth. We return to the original demographic shock featuring $\pi_{1}=0.05 \%$ per annum and an old-age dependency ratio of $46 \%\left(\eta_{1,1}=0.0581\right.$ and $\left.\beta_{1}=0.0151\right)$. As was pointed out by Broer (2001, p. 89), "in an ageing society, both the health insurance system and the pension system impose an increasing burden on households. ... Thus as the share of elderly in the population grows, the contribution base [of the public health insurance system, HM] shrinks at the same time when demand for health care increases." In short, it can be argued that the public health insurance system itself contains elements of a PAYG type, i.e. it taxes the young (and healthy) and provides resources to the old (and infirm).

Whereas it is beyond the scope of the present paper to fully model the health insurance system, we take from Broer's analysis the idea that the PAYG system may be broader than just the public pension system itself. We study the quantitative consequences of PAYG system size in columns (d)-(g) in Table 3. Column (d) shows what happens to the initial steady-state economy if the contribution rate is increased from $\theta_{0}=0.07$ to $\theta_{1}=0.15$. The comparison between columns (a) and (d) reveals that there is a huge drop in the growth rate, from $g=1.91 \%$ to $g=1.19 \%$ per annum. Intuitively the larger PAYG system takes more from the young and gives more to the old. This chokes off private savings and retards economic growth.

Columns (e)-(g) in Table 3 shows the effects of the original demographic shock under DC, DB, and RA. The growth increases under all scenarios with the largest effect occurring under the DC system. Interestingly, whereas the growth effect was smallest for the RA case in the original model with the narrowly defined PAYG system, for a large PAYG system it is smallest for the DB scenario.

\subsection{Limitations}

A few words of caution are in place when interpreting our conclusions. There are several limitations. First, our analysis consists of steady-state comparisons and space considerations prevent us from studying the transitional dynamics of a longevity shock. Although we find that in the steady state a longevity shock has beneficial effects on growth, it need not be the case that transition is monotonic. Second, we have merely analyzed growth but not individual welfare. However, as we assume exogenous labour supply higher growth automatically translates into higher welfare because discounted income of individuals increases. Third, we have assumed that labour supply and the retirement age are exogenous. We have chosen this approach here in order to keep the model as simple as possible. Indeed, endogenization of both the hours decision over the life cycle and/or the retirement date is fairly straightforward-see e.g. Heijdra and Romp (2009) and Heijdra and Mierau (2009, 2010). Fourth, we have ignored aggregate risk and the risk-sharing properties of pension systems. The interested reader is referred to Bovenberg and Uhlig (2008) who apply a two-period stochastic overlapping generations model featuring endogenous growth to study the consequences of particular pension systems on risk-sharing between generations. Finally, we have studied a closed economy. This is not a convincing representation of the Dutch economy which is 
extremely open and small in world markets. However, aging is a global phenomenon. Hence, to model a small open economy with fixed factor prices is equally unconvincing. Here we have chosen the closed economy framework to zoom in on the global consequences of ageing on capital accumulation and economic growth- the big picture.

\section{Conclusions}

We develop a macroeconomic model that is firmly grounded in the microeconomic environment of the individual. In contrast to the highly stylized models in the tradition of Blanchard (1985) we are able to replicate individual profiles for both consumption and savings. In addition, and in contrast to the very detailed computable general equilibrium models, we are still able to clearly analyze the mechanisms that are at play in the interaction between microeconomic behaviour and macroeconomic outcomes.

For the purpose at hand we have kept the model as simple as possible. The model, however, is very flexible in its very nature. In earlier work we have used a more elaborate version of the model to study issues relating to capital market imperfections (Heijdra and Mierau 2009) and taxation issues (Heijdra and Mierau 2010). In future work we seek to further study the nebulous relationship between aging and economic growth in a model where also the labour market participation decision (concerning entry and retirement) is made endogenous.

With the current version of the model we study the relationship between aging and economic growth and the mediating role that government policy has on this relationship. We find that, in principle, aging increases the economic growth rate. However, if a defined benefit system is in place the growth effect weakens somewhat because of the increase in the contribution rate necessary to finance the additional pensioners. In order to circumvent this adverse effect on the growth rate the government might consider to switch to a defined contribution system or to increase the retirement age. Surprisingly, we find that the latter policy option has adverse effects on the economy. This is due to a weaker savings reaction to the shortened retirement horizon.

Acknowledgements We thank Jan van Ours and Laurie Reijnders for helpful comments and remarks. This paper was written during the second author's visit to the Department of Economics of the University of Washington. The department's hospitality is gracefully acknowledged.

Open Access This article is distributed under the terms of the Creative Commons Attribution Noncommercial License which permits any noncommercial use, distribution, and reproduction in any medium, provided the original author(s) and source are credited.

\section{References}

Abel, A. B. (1986). Capital accumulation and uncertain lifetimes with adverse selection. Econometrica, 54, 1079-1098.

Alessie, R., \& de Ree, J. (2009). Explaining the hump in life cycle consumption profiles. De Economist, 157, 107-120.

Attanasio, O. P., \& Weber, G. (1995). Is consumption growth consistent with intertemporal optimization? Evidence from the consumer expenditure survey. Journal of Political Economy, 103, 1121-1157. 
Auerbach, A. J., \& Kotlikoff, L. J. (1987). Dynamic fiscal policy. Cambridge: Cambridge University Press.

Blanchard, O.-J. (1985). Debts, deficits, and finite horizons. Journal of Political Economy, 93, 223-247.

Bloom, D. E., Canning, D., \& Fink, G. (2008). Population aging and economic growth. Working Paper 320. Commission on Growth and Development, Washington, DC.

Boucekkine, R., de la Croix, D., \& Licandro, O. (2002). Vintage human capital, demographic trends, and endogenous growth. Journal of Economic Theory, 104, 340-375.

Bovenberg, A. L., \& Uhlig, H. (2008). Pension systems and the allocation of macroeconomic risk. In NBER International Seminar on Macroeconomics 2006 (pp. 241-323)

Broer, D. P. (2001). Growth and welfare distribution in an ageing society: An applied general equilibrium analysis for the Netherlands. De Economist, 149, 81-114.

Bütler, M. (2001). Neoclassical life-cycle consumption: A textbook example. Economic Theory, 17, 209-221.

d'Albis, H. (2007). Demographic structure and capital accumulation. Journal of Economic Theory, $132,411-434$.

De Waegenaere, A., Melenberg, B., \& Stevens, R. (2010). Longevity risk. De Economist, 158, 151-192.

Fehr, H. (2009). Computable stochastic equilibrium models and their use in pension- and ageing research. De Economist, 157, 359-416.

Fernandez-Villaverde, J., \& Krueger, D. (2007). Consumption over the life cycle: Facts from consumer expenditure survey data. Review of Economics and Statistics, 89, 552-565.

Finkelstein, A., \& Poterba, J. (2002). Selection effects in the United Kingdom individual annuities market. Economic Journal, 112(476), 28-50.

Fougère, M., \& Mérette, M. (1999). Population ageing and economic growth in seven OECD countries. Economic Modelling, 16, 411-427.

Friedman, B. M., \& Warshawsky, M. J. (1988). Annuity prices and saving behavior in the United States. In Z. Bodie, J. B. Shoven, \& D. A. Wise (Eds.), Pensions in the US economy (pp. 53-77). Chicago: University of Chicago Press.

Futagami, K., \& Nakajima, T. (2001). Population aging and economic growth. Journal of Macroeconomics, 23, 31-44.

Gourinchas, P.-O., \& Parker, J. A. (2002). Consumption over the life cycle. Econometrica, 70, 47-89.

Hansen, G. D. (1993). The cyclical and secular behaviour of the labour input: Comparing efficiency units and hours worked. Journal of Applied Econometrics, 8, 71-80.

Hansen, G. D., \& İmrohoroğlu, S. (2008). Consumption over the life cycle: The role of annuities. Review of Economic Dynamics, 11, 566-583.

Heijdra, B. J., \& Mierau, J. O. (2009). Annuity market imperfection, retirement and economic growth. Working Paper 2717, CESifo, München.

Heijdra, B. J., \& Mierau, J. O. (2010). Growth effects of consumption and labour-income taxation in an overlapping-generations life-cycle model. Macroeconomic Dynamics, 14.

Heijdra, B. J., Mierau, J. O., \& Reijnders, L. S. M. (2010). The tragedy of annuitization. Working Paper 3141, CESifo, München.

Heijdra, B. J., \& Reijnders, L. S. M. (2009). Economic growth and longevity risk with adverse selection. Working Paper 2898, CESifo, München.

Heijdra, B. J., \& Romp, W. E. (2006). Ageing and growth in the small open economy. Working Paper 1740, CESifo, München.

Heijdra, B. J., \& Romp, W. E. (2008). A life-cycle overlapping-generations model of the small open economy. Oxford Economic Papers, 60, 89-122.

Heijdra, B. J., \& Romp, W. E. (2009). Retirement, pensions, and ageing. Journal of Public Economics, 93, 586-604.

Huggett, M. (1996). Wealth distribution in life-cycle economies. Journal of Monetary Economics, 38, 469-494.

Lallemand, T., \& Rycx, F. (2009). Are older workers harmful for firm productivity? De Economist, 157, 273-292.

McGrattan, E. R., \& Rogerson, R. (2004). Changes in hours worked, 1950-2000. Federal Reserve Bank of Minneapolis Quarterly Review, 28, 14-33.

Pissarides, C. A. (1980). The wealth-age relation with life insurance. Economica, 47, 451-457.

Prettner, K. (2009). Population ageing and endogenous economic growth. Working Paper 8-2009, Vienna Institute of Demography, Vienna, Austria. 
Ríos-Rull, J. V. (1996). Life-cycle economies and aggregate fluctuations. Review of Economic Studies, 63, 465-489.

Romer, P. M. (1989). Capital accumulation in the theory of long-run growth. In R. J. Barro (Ed.), Modern business cycle theory (pp. 51-127). Oxford: Basil Blackwell.

Sims, C. (1980). Macroeconomics and reality. Econometrica, 48(1), 1-48.

van Ours, J. (2009). Will you still need me: When I'm 64? De Economist, 157, 441-460.

Yaari, M. E. (1965). Uncertain lifetime, life insurance, and the theory of the consumer. Review of Economic Studies, 32, 137-150. 